were taken by a Greek friend to a modest taverna in the Plaka district where we enjoyed a lively atmosphere and fine cuisine. But it seems our more prosperous colleagues were less fortunate, as, despite their sumptuous surroundings, the food rations were, once again, meagre. We were told that the seating arrangements were of such an intimate nature that it rendered the transfer of food from plate to mouth almost impossible. As we were entertained by an excellent bouzouki band, our colleagues at the Hilton were treated to a rendition of Eurovision pop contest song favourites.

Despite the variability of the scientific programme, and some of the difficulties we have touched upon, we enjoyed our first foray into the international conference scene immensely. We particularly valued the opportunity of meeting so many interesting people from other countries around the world, and talking informally about their research interests.

However, we quickly learnt from our more experienced colleagues that to admit one is enjoying oneself is to reveal a shameful lack of sophistication. The correct code of conduct at all such occasions is to disparage everything and bemoan one's cruel fate at being obliged to attend so many international gatherings.

Since we have not yet mastered this art, we are eagerly looking forward to the IXth World Congress in Rio.

\title{
COMPETITION! COMPETITION! COMPETITION!
}

\section{Christmas Limerick Competition}

In lighter vein, the Bulletin is setting a Limerick Competition with a psychiatric flavour - open to all Fellows, Members, Inceptors, and Affiliates of the College, who may, of course, be helped by their next of kin.

The competition is to complete a limerick beginning with one of the following first lines:

"There was a disciple of Freud ...."

"I've been to the Maudsley she cried ....."

"There once was an MRCPsych ....."
Three prizes of books will be awarded for the wittiest and most original entries, and the competition will be judged by a small panel of eminent Professors in Psychiatry.

We are hoping to publish the best entries, so could you please err on the side of respectability!

Entries should be sent to: Dr Adrian Yonace, Consultant Psychiatrist, St Ann's Hospital, Haven Road, Canford Cliffs, Poole BH13 7LN, to arrive by Christmas Eve.

Good Luck! 